\title{
Relationship Between Cardiac Autonomic Neuropathy and Atherosclerosis in Patients with Diabetes Mellitus
}

\author{
Sarka Mala ${ }^{1 *}$, Lucie Hoskovcova ${ }^{1}$, Lucie Riedlbauchova ${ }^{2}$, Tomas Nedelka ${ }^{3}$ and Jan Broz ${ }^{1}$ \\ ${ }^{1}$ Internal Medicine Department, University Hospital Motol, Czech Republic \\ ${ }^{2}$ Department of Cardiology, University Hospital Motol, Czech Republic \\ ${ }^{3}$ Department of Neurology, University Hospital Motol, Czech Republic
}

Submission: September 28, 2018; Published: October 10, 2018

*Corresponding author: Sarka Mala, Internal Medicine Department, University Hospital Motol, V Uvalu 84, 15006, Prague, Czech Republic, Email-sarkamal@seznam.cz

\begin{abstract}
Cardiovascular disease is the major cause of death in diabetic patients. Diabetes mellitus patients have a 4-fold-higher risk of having a cardiovascular event than people without diabetes. Cardiac autonomic neuropathy is a frequent and severe complication of diabetes mellitus. Definite cardiac autonomic neuropathy is present in one fifth of diabetic patients. Cardiac autonomic neuropathy diagnosis is associated with a 5 -fold increase in mortality, higher prevalence of silent myocardial ischemia as well as systolic and diastolic left ventricular dysfunction. In the last several years many works described a significant relationship between cardiac autonomic neuropathy and atherosclerotic vascular disease in type 1 and type 2 diabetes mellitus population. Our review focuses on possible pathophysiological pathways binding these two important diabetic complications.
\end{abstract}

Keywords: Autonomic neuropathy; Diabetes mellitus; Atherosclerosis; Arterial stiffness

\section{Introduction}

Patients with type 1 and type 2 diabetes mellitus have significantly higher risk of cardiovascular disease including coronary artery disease(CAD), stroke, and peripheral arterial disease comparing to non-diabetic population [1-3]. Cardiovascular disease is the major cause of death in diabetic patients (approximately 70\%) [4,5]. Type 2 diabetes mellitus patients have a 4-fold-higher risk of having a cardiovascular event than people without diabetes after adjusting to common risk factors of atherosclerosis, such as age, tobacco smoking, obesity, hyperlipidemia and hypertension. Major cardiovascular event (such as myocardial infarction, coronary revascularization, stroke, acute coronary heart disease death) is 3 times more often in type 1 diabetic men and up to 7 times more often in type 1 diabetic women $[5,6]$.

Prolonged hyperglycemia is considered to be a main cause of diabetic microvascular and macrovascular complications $[4,7,8]$. Chronic hyperglycemia induces the production of advanced glycation end products (AGEs) through thenon-enzymatic glycation process, alters intracellular signaling cascades (protein kinase $\mathrm{C}$ activation), and increases oxidative stress. All these mechanisms interact and lead to many structural and functional changes of the vascular wall inducing the atherosclerosis development [9]. Hy perglycemia also increases platelet aggregation, risk of thrombus formation and atherosclerosis progression [10].

In patients with type 2 diabetes mellitus, obesity and fatty tissue accumulation lead to lipid metabolism changes and proinflammatory markers production. In these subjects, insulin resistance is critically involved in vascular dysfunction $[11,12]$. Cardiac autonomic neuropathy (CAN) is a frequent and severe complication of diabetes mellitus. Definite CAN is present in one fifth of diabetic patients [13]. CAN diagnosis is associated with a 5-fold increase in mortality comparing to diabetic patients without CAN, and a higher prevalence of silent myocardial ischemia as well as systolic and diastolic left ventricular dysfunction [14-16]. CAN incidence correlates to QT prolongation and increase the risk of malignant arrhythmias and sudden cardiac death [17]. In the last several years many works described a significant relationship between cardiac autonomic neuropathy and atherosclerotic vascular disease in type 1 and type 2 diabetes mellitus population [18-24].

Are cardiac autonomic neuropathy together with accelerated atherosclerosis only products of prolonged unsatisfactory metabolic compensation or is there a pathophysiological mechanism 


\section{Current Research in Diabetes \& Obesity Journal}

that promotes atherosclerosis development in patients suffering CAN? We would like to address these questions in our review.

\section{Risk factors of CAN and atherosclerosis}

Age, diabetes mellitus, high cholesterol and low density lipoprotein levels, low level of high density lipoprotein, hypertension, tobacco smoke, obesity and inactive lifestyle are now considered to be major risk factors of atherosclerosis [25].

Some of these factors were also found to be risk markers of CAN. A meta-analysis of Dafaalla et al. from 2016 found that age, duration of diabetes, glycated hemoglobin level, BMI, serum triglycerides, hypertension and incidence of microvascular complications are directly related to the risk of CAN development in type 1 diabetes mellitus [26]. Similar findings applies for CAN in type 2 diabetes mellitus. Reduced heart rate variability(an indicator of CAN) in type 2 diabetes mellitus patients is also in association with obesity and smoking [16]. Poor glycemic control seems to be a major risk for CAN progression in diabetic patient [27-29]. Many risk factors of atherosclerosis and diabetic CAN overlap, especially in type 2 diabetes mellitus patients. But what is the exact mechanism of CAN development? Is it only a result of vasa nervorum ischemia or do also other pathogenic pathways take a part?

\section{Pathogenesis of CAN}

Pathogenesis of CAN is complex, multifactorial and not entirely clear. Multiple ethiological hypotheses were proposed including hyperglycemia induced nerve fibers injury, autoimmune damage and neurohormonal growth factor deficiency $[15,29,30]$.

\section{Hyperglycemia}

Long term hyperglycemia is considered to be a leading cause of micro and macrovascular complications of diabetes mellitus. Hyperglycemia leads through the alteration of many metabolic pathways to endothelial dysfunction, decreased neuronal blood flow and nerve fiber damage. Excess of glucose activates the polyol pathway leading to sorbitol accumulation. NADPH is consumed as a coenzyme in this process. Relative deficiency of NADPH may cause impaired NO synthesis and decreased nerve blood flow [15,31]. Hyperglycemia induced metabolic changes result in increased free radicals production and oxidative stress that lead to vascular endothelium damage [15]. Accelerated advanced glycation end (AGE) products formation alters the membrane permeability as well as neuronal and endothelial function [32]. Increased formation of diacylglycerol lead to the subsequent activation of protein kinase $\mathrm{C}(\mathrm{PKC})$. PKC pathway affects the regulation of endothelial permeability, vasoconstriction, extracellular matrix synthesis, abnormal angiogenesis and cytokine activation [33]. All these mechanisms result in functional and structural changes of vessels (including vasa nervorum) and nerve fibers.

\section{Autoimmunity}

The role of autoimmunity on diabetic autonomic neuropathy is also discussed. Several studies proved the independentassociation of nervous tissue antibodies and CAN presence in patients with
T1DM [15,29,34-36]. One of the most recent prospective study with adolescent T1DM patients was published in 2014. Zanone et al. has followed 66 patients for 16 years. 19 of them had circulating autobodies(Ab) to autonomic tissues. Prevalence of abnormal cardiovascular autonomic tests and autonomic symptoms were higher in Ab-positive (68 and 26\%) than Ab-negative (32 and 4\%) patients $(\mathrm{P}<0.05)$ independent of glycemic control [37]. Study of Shigeta et al. found that the presence of circulating sulfatide and phospholipid antibodies correlates with diabetic neuropathy in 68 T2DM patients [38,39]. However more studies are needed to prove the role of autoimmunity on diabetic autonomic neuropathy in T2DM patients.

\section{Genetic predisposition}

Many genes were found to have an association with the development or progression of diabetic neuropathy (i.e. ACE, MTHFR, GST, GL01, APOE, TCF7L2, VEGF, IL-4, GPX1, eNOS, ADRA2B, GFRA2, MIR146A, MIR128A) [40]. Some of the studies were focused to find gene polymorphisms correlation with diabetic autonomic neuropathy. Genes associated with autonomic dysfunction code for example an antioxidant enzyme (Glutathione S-transferase), transcription factor (TCF7L2 gene) or autonomic nervous sysem receptor (alpha2B-adrenergic receptor) [40-42].

\section{Possible pathogenic pathways binding CAN and athe- rosclerosis progression}

It seems that autonomic neuropathy is not only a microvascular complication, but several pathophysiological mechanisms are involved in its development. Let's have a look from the other side. How could CAN contribute to atherosclerosis development and progression?

\section{Non-dipping and Hypertension}

The autonomic nervous system is responsible for the optimal regulation of the heart rate, strength of cardiac muscle contraction and vessel tone. The renin-angiotensin-aldosterone system controls the body fluid volume. Both of these systems interact and regulate the blood pressure. Blood pressure, along with the heart rate, physiologically decreases during the sleep period as a result of the higher tone of the parasympathetic nervous system. This phenomenon is called nocturnal dipping and it is at least $10 \%$ drop of blood pressure in comparison to average daily values. It is known that nerve fiber loss is length-dependent. That explains predominant parasympathetic (vagus nerve) impairment in early stages of CAN [31]. Vagal nerve dysfunction and relative hyperactivity of the sympathetic nervous system in early stages of CAN is the most probable cause of insufficient drop of blood pressure during the sleep (so called blood pressure "nondipping ") or even rise of blood pressure during the night (so called „reverse dipping") $[27,43,44]$.

Nondipping and reverse dipping is associated with left ventricular hypertrophy and cardiovascular events [45-48]. A meta-analysis of Cuspidi et al. proved the association between nondipping and increased risk of subclinical atherosclerosis [49]. Moreover a prospective study which monitored 75 adolescent 
T1DM patients found that the abnormal blood pressure pattern during the night period also precedes the development of microalbuminuria (marker of glomerular and vascular dysfunction) [50]. All these studies support a statement of Vinik and his colleagues from 2003 who suggested that an impaired circadian pattern of sympathovagal activity with higher blood pressure values during the night and subsequent complications could represent an important link between CAN and an increased risk of mortality in diabetic patients [15].

\section{Arterial stiffness}

Thera are also data indicating that CAN is associated with arterial stiffness [51-53]. Arterial stiffness leads to higher arterial wall resistance and increases systolic blood pressure. Higher systolic blood pressure promotes atherosclerosis development. Again we are confronted with the question whether CAN and arterial stiffness are common results of chronic bad diabetic compensation or whether they interact. As we discussed above, early stages of CAN are accompanied by prevalent parasympathetic impairment leading to relative hyperactivity of sympathetic nervous system. Higher sympathetic tone leads to tachycardia in rest. In rat animal models, an artificial increase of heart rate determines the reduction of arterial distensibility [54-56]. Moreover, vagal denervation is associated with higher procollagen mRNA levels in the wall of affected vessels [57]. Sympathetic denervation may cause dedifferentiation of vascular smooth muscle cells and intima thickening [58]. These findings suggest that the autonomic nervous system alterations have a negative trophic effect on arterial wall and could lead to increased arterial stiffness. This hypothesis seems to be supported by a prospective study of Prince et al. published in 2010. It showed that CAN (expressed as decreased heart rate variability in deep breathing test) is associated with increased arterial stiffness 18 years later in type 1 diabetes mellitus patients [59].

\section{Inflammatory pathway}

Experimental studies showed that the autonomic nervous system modulates the systemic inflammatory response through the cholinergic anti-inflammatory pathway $[60,61]$. Rodrigues et al. [19] who published in 2010 an interesting study that proved that reduced heart rate variability(marker of CAN) predicts the progression of coronary artery calcification in adults with and without T1DM, suggested that autonomic neuropathy leading to pro-inflammatory state could represent one pathway leading to atherosclerosis progression [19]. A study from 2017 found an association of lower heart rate variability(HRV) and white blood cells count(WBCC), this study also described an inverse association of inflammatory markers(WBCC and CRP) with baroreflex sensitivity and carotid plaque area [62]. Another study described an association of lower HRV parameters, presence of depression and higher IMT with CRP and IL6 [63]. Nevertheless more studies are needed to confirm how could autonomic dysfunction activate the inflammatory system and promote atherosclerosis.

All mentioned pathophysiological pathways binding CAN and atherosclerosis are summarized on simplified schema (Figure 1).

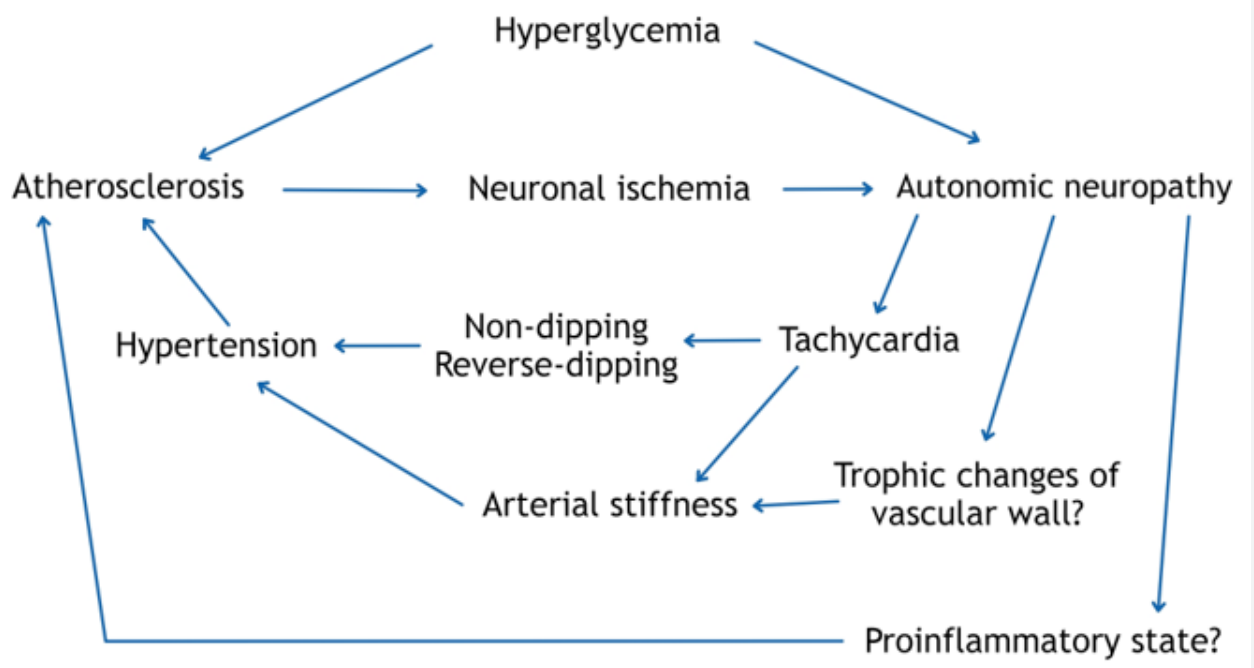

Figure 1: Discussed pathophysiological pathways binding CAN and atherosclerosis.

\section{Discussion}

Our review focused on the relationship between CAN and atherosclerosis development in diabetic patients. Although some risk factors of atherosclerosis overlap with the risk factors of CAN, it seems that the pathophysiology of CAN is more complex and multifactorial. Several small studies found a significant correlation between the presence of circulating autonomic tissue autobodies and diabetic autonomic neuropathy. The role of genetic polymorphisms and epigenetic changes of several genes associated with autonomic function is also discussed.

It seems that both of these diabetic complications interact and mutually affect the progression of each other. We discussed the possible pathways (heart rate and blood pressure increase, trophic changes of arterial wall, arterial stiffness, pro-inflammatory state) through which CAN may contribute to atherosclerosis progression. Future prospective studies on young diabetic patients with 


\section{Current Research in Diabetes \& Obesity Journal}

good glycemic control and free of macrovascular complications could help to identify the exact pathophysiological mechanisms between these two units and hopefully find a way how to decrease cardiovascular mortality in diabetic patients.

\section{References}

1. American Diabetes association (1989) Consensus Statement: Role of cardiovascular risk factors in prevention and treatment of macrovascular disease in diabetes. Diabetes Care 12(8): 573-579.

2. Stamler J, Vaccaro O, Neaton JD, Wentworth D (1993) Diabetes, other risk factors, and 12-yr cardiovascular mortality for men screened in the Multiple Risk Factor Intervention Trial. Diabetes Care 16(2): 434444

3. Schwartz CJ, Valente AJ, Sprague EA, Kelley JL, Cayatte AJ, et al. (1992) Pathogenesis of the atherosclerotic lesion. Implications for diabetes mellitus. Diabetes Care 15(9): 1156-1167.

4. Laakso M (1999) Hyperglycemia and cardiovascular disease in type 2 diabetes. Diabetes 48(5): 937-942.

5. de Ferranti SD, de Boer IH, Fonseca V, Fox CS, Golden SH, et al. (2014) Type 1 diabetes mellitus and cardiovascular disease: a scientific statement from the American Heart Association and American Diabetes Association. Diabetes Care 130(13):1110-1130.

6. Buyken AE, von Eckardstein A, Schulte H, Cullen P, Assmann G (2007) Type 2 diabetes mellitus and risk of coronary heart disease: results of the 10-year follow-up of the PROCAM study. Eur J Cardiovasc Prev Rehabil 14(2): 230-236.

7. Grundy SM, Benjamin IJ, Burke GL, Chait A, Eckel RH, et al. (1997) Diabetes and cardiovascular disease: a statement for healthcare professionals from the American Heart Association. Circulation 100(10): 1134-1146.

8. Diabetes Control and Complications Trial Research Group, Nathan DM, Genuth S, Lachin J, Cleary P, et al. (1993) The effect of intensive treatment of diabetes on the development and progression of longterm complications in insulin-dependent diabetes mellitus. N Engl Med 329(14): 977-986.

9. Aronson D, Rayfield EJ (2002) How hyperglycemia promotes atherosclerosis: molecular mechanisms. Cardiovasc Diabetol 1:1.

10. Grant PJ (2007) Diabetes mellitus as a prothrombotic condition. J Intern Med 262(2): 157-172.

11. Kim JA, Montagnani M, Koh KK, Quon MJ (2006) Reciprocal relationships between insulin resistance and endothelial dysfunction: molecular and pathophysiological mechanisms. Circulation 113(15): 1888-1904.

12. Paneni F, Beckman JA, Creager MA, Cosentino F (2013) Diabetes and vascular disease: pathophysiology, clinical consequences, and medical therapy: part I. Eur Heart J 34(31): 2436-2443.

13. Spallone V, Ziegler D, Freeman R, Bernardi L, Frontoni S, et al. (2011) Cardiovascular autonomic neuropathy in diabetes: clinical impact, assessment, diagnosis, and management. Diabetes Metab Res Rev 27(7): 639-653.

14. Maser RE, Mitchell BD, Vinik AI, Freeman R (2003) The association between cardiovascular autonomic neuropathy and mortality in individuals with diabetes: a meta-analysis. Diabetes Care 26(6): 18951901.

15. Vinik AI, Maser RE, Mitchell BD, Freeman R (2003) Diabetic autonomic neuropathy. Diabetes Care 26(5): 1553-1579.

16. Vinik AI, Ziegler D (2007) Diabetic cardiovascular autonomic neuropathy. Circulation 115(3): 387-397.

17. Ewing DJ, Boland O, Neilson JM, Cho CG, Clarke BF (1991) Autonomic neuropathy, QT interval lengthening, and unexpected deaths in male diabetic patients. Diabetologia 34(3): 182-185.

18. Meyer C, Milat F, McGrath BP, Cameron J, Kotsopoulos D, et al. (2004) Vascular dysfunction and autonomic neuropathy in Type 2 diabetes. Diabet Med 21(7): 746-751.

19. Rodrigues TC, Ehrlich J, Hunter CM, Kinney GL, Rewers M, et al. (2010) Reduced heart rate variability predicts progression of coronary artery calcification in adults with type 1 diabetes and controls without diabetes. Diabetes Technol Ther 12(12): 963-969.

20. Fakhrzadeh H, Yamini-Sharif A, Sharifi F, Tajalizadekhoob Y, Mirarefin M, et al. (2012) Cardiac autonomic neuropathy measured by heart rate variability and markers of subclinical atherosclerosis in early type 2 diabetes. ISRN Endocrinol 2012: 168264.

21. Jung CH, Baek AR, Kim KJ, Kim BY, Kim CH, et al. (2013) Association between Cardiac Autonomic Neuropathy, Diabetic Retinopathy and Carotid Atherosclerosis in Patients with Type 2 Diabetes. Endocrinol Metab (Seoul) 28(4): 309-319.

22. Canani LH, Copstein E, Pecis M, Friedman R, Leitão CB, et al. (2013) Cardiovascular autonomic neuropathy in type 2 diabetes mellitus patients with peripheral artery disease. Diabetol Metab Syndr 5(1): 54.

23. Mala S, Potockova V, Hoskovcova L, Pithova P, Brabec M, et al. (2017) Cardiac autonomic neuropathy may play a role in pathogenesis of atherosclerosis in type 1 diabetes mellitus. Diabetes Res Clin Pract 134: 139-144.

24. Dayem SM, Battah AA, Bohy Ael M (2015) Cardiovascular Autonomic Neuropathy and Early Atherosclerosis in Adolescent Type 1 Diabetic Patient. Open Access Maced J Med Sci 3(4): 681-688.

25. Rafieian-Kopaei M, Setorki M, Doudi M, Baradaran A, Nasri H (2014) Atherosclerosis: process, indicators, risk factors and new hopes. Int J Prev Med 5(8): 927-946.

26. Dafaalla MD, Nimir MN, Mohammed MI, Ali OA, Hussein A (2016) Risk factors of diabetic cardiac autonomic neuropathy in patients with type 1 diabetes mellitus: a meta-analysis. Open Heart 3(2): e000336.

27. Bissinger A (2017) Cardiac Autonomic Neuropathy: Why Should Cardiologists Care about That? J Diabetes Res 2017: 5374176.

28.Ziegler D (1994) Diabetic cardiovascular autonomic neuropathy: prognosis, diagnosis and treatment. Diabetes Metab Rev. 10(4): 339383.

29. Dimitropoulos G, Tahrani AA, Stevens MJ (2014) Cardiac autonomic neuropathy in patients with diabetes mellitus. World J Diabetes 5(1): 17-39.

30. Yasuda H, Terada M, Maeda K, Kogawa S, Sanada M, et al. (2003) Diabetic neuropathy and nerve regeneration. Prog Neurobiol 69(4): 229-285.

31. Yagihashi S, Yamagishi S, Wada R (2007) Pathology and pathogenetic mechanisms of diabetic neuropathy: correlation with clinical signs and symptoms. Diabetes Res Clin Pract 77 Suppl 1: S184-189.

32. Balcıŏlu AS, Müderrisoğlu H (2015) Diabetes and cardiac autonomic neuropathy: Clinical manifestations, cardiovascular consequences, diagnosis and treatment. World J Diabetes 6(1): 80-91.

33. Das Evcimen N, King GL (2007) The role of protein kinase C activation and the vascular complications of diabetes. Pharmacol Res 55(6): 498510.

34. Rabinowe SL, Brown FM, Watts M, Smith AM (1990) Complementfixing antibodies to sympathetic and parasympathetic tissues in IDDM. Autonomic brake index and heart-rate variation. Diabetes Care 13(10): 1084-1088.

35. Ejskjaer N, Arif S, Dodds W, Zanone MM, Vergani D, et al. (1999) Prevalence of autoantibodies to autonomic nervous tissue structures in Type 1 diabetes mellitus. Diabet Med 16(7): 544-549. 


\section{Current Research in Diabetes \& Obesity Journal}

36. Vinik AI, Leichter SB, Pittenger GL, Stansberry KB, Holland MT, et al. (1995) Phospholipid and glutamic acid decarboxylase autoantibodies in diabetic neuropathy. Diabetes Care 18(9): 1225-1232.

37. Zanone MM, Raviolo A, Coppo E, Trento M, Trevisan M, et al. (2014) Association of autoimmunity to autonomic nervous structures with nerve function in patients with type 1 diabetes: a 16-year prospective study. Diabetes Care 37(4): 1108-1115

38. Shigeta H, Yamaguchi M, Nakano K, Obayashi H, Takemura R, et al (1997) Serum autoantibodies against sulfatide and phospholipid in NIDDM patients with diabetic neuropathy. Diabetes Care 20(12): 1896-1899.

39. Politi C, Ciccacci C, D’Amato C, Novelli G, Borgiani P, et al. (2016) Recent advances in exploring the genetic susceptibility to diabetic neuropathy. Diabetes Res Clin Pract 120:198-208.

40. Vojtková J, Ďurdík P, Čiljaková M, Michnová Z, Turčan T, et al. (2013) The association between glutathione S-transferase T1 and M1 gene polymorphisms and cardiovascular autonomic neuropathy in Slovak adolescents with type 1 diabetes mellitus. J Diabetes Complications 27(1): 44-48.

41. Ciccacci C, Di Fusco D, Cacciotti L, Morganti R, D’Amato C, et al. (2013) TCF7L2 gene polymorphisms and type 2 diabetes: association with diabetic retinopathy and cardiovascular autonomic neuropathy. Acta Diabetol 50(5): 789-799.

42. Sivenius K, Niskanen L, Laakso M, Uusitupa M (2003) A deletion in the alpha2B-adrenergic receptor gene and autonomic nervous function in central obesity. Obes Res 11(8): 962-970.

43. Heart rate variability: standards of measurement, physiological interpretation and clinical use. Task Force of the European Society of Cardiology and the North American Society of Pacing and Electrophysiology (1996) Circulation 93(5): 1043-1065.

44. Spallone V, Maiello MR, Cicconetti E, Pannone A, Barini A, et al. (2001) Factors determining the 24 -h blood pressure profile in normotensive patients with type 1 and type 2 diabetes. J Hum Hypertens 15(4): 239246.

45. Spallone V, Bernardi L, Ricordi L, Soldà P, Maiello MR, et al. (1993) Relationship between the circadian rhythms of blood pressure and sympathovagal balance in diabetic autonomic neuropathy. Diabetes 42(12): 1745-1752.

46. Mancia G, Zanchetti A, Agabiti-Rosei E, Benemio G, De Cesaris R, et al. (1997) Ambulatory blood pressure is superior to clinic blood pressure in predicting treatment-induced regression of left ventricular hypertrophy. SAMPLE Study Group. Study on Ambulatory Monitoring of Blood Pressure and Lisinopril Evaluation. Circulation 95(6):14641470 .

47. Verdecchia P, Schillaci G, Guerrieri M, Gatteschi C, Benemio G, et al. (1990) Circadian blood pressure changes and left ventricular hypertrophy in essential hypertension. Circulation 81(2): 528-536.

48. Kuwajima I, Suzuki Y, Shimosawa T, Kanemaru A, Hoshino S, et al. (1992) Diminished nocturnal decline in blood pressure in elderly hypertensive patients with left ventricular hypertrophy. Am Heart J 123(5): 1307-1311.
49. Cuspidi C, Sala C, Tadic M, Gherbesi E, Grassi G, et al. (2016) Nondipping pattern and carotid atherosclerosis: a systematic review and metaanalysis. J Hypertens 34(3): 385-391.

50. Lurbe E, Redon J, Kesani A, Pascual JM, Tacons J, et al. (2002) Increase in nocturnal blood pressure and progression to microalbuminuria in type 1 diabetes. N Engl J Med 347(11): 797-805.

51. Liatis S, Alexiadou K, Tsiakou A, Makrilakis K, Katsilambros N, et al (2011) Cardiac autonomic function correlates with arterial stiffness in the early stage of type 1 diabetes. Exp Diabetes Res 2011: 957901.

52. Bagherzadeh A, Nejati-Afkham A, Tajallizade-Khoob Y, Shafiee A, Sharifi F, et al. (2013) Association of cardiac autonomic neuropathy with arterial stiffness in type 2 diabetes mellitus patients. J Diabetes Metab Disord 12(1): 55

53. Theilade S, Lajer M, Persson F, Joergensen C, Rossing P (2013) Arterial stiffness is associated with cardiovascular, renal, retinal, and autonomic disease in type 1 diabetes. Diabetes Care 36(3): 715-721.

54. Mangoni AA, Mircoli L, Giannattasio C, Mancia G, Ferrari AU (1997) Effect of sympathectomy on mechanical properties of common carotid and femoral arteries. Hypertension 30(5): 1085-1088.

55. Mircoli L, Mangoni AA, Giannattasio C, Mancia G, Ferrari AU (1999) Heart rate-dependent stiffening of large arteries in intact and sympathectomized rats. Hypertension 34(4 Pt 1): 598-602.

56. Mangoni AA, Mircoli L, Giannattasio C, Ferrari AU, Mancia G (1996) Heart rate-dependence of arterial distensibility in vivo. J Hypertens 14(7): 897-901.

57. Carver TW Jr, Srinathan SK, Velloff CR, Pérez Fontán JJ (1997) Increased type I procollagen mRNA in airways and pulmonary vessels after vagal denervation in rats. Am J Respir Cell Mol Biol 17(6): 691-701.

58. Kacem K, Bonvento G, Seylaz J (1997) Effect of sympathectomy on the phenotype of smooth muscle cells of middle cerebral and ear arteries of hyperlipidaemic rabbits. Histochem J 29(4): 279-286.

59. Prince CT, Secrest AM, Mackey RH, Arena VC, Kingsley LA, et al. (2010) Cardiovascular autonomic neuropathy, HDL cholesterol, and smoking correlate with arterial stiffness markers determined 18 years later in type 1 diabetes. Diabetes Care 33(3): 652-657.

60. Borovikova LV, Ivanova S, Zhang M, Yang H, Botchkina GI, et al. (2000) Vagus nerve stimulation attenuates the systemic inflammatory response to endotoxin. Nature 405(6785): 458-462.

61. Wang H, Yu M, Ochani M, Amella CA, Tanovic M, et al. (2003) Nicotinic acetylcholine receptor alpha7 subunit is an essential regulator of inflammation. Nature 421(6921): 384-388.

62.Ulleryd MA, Prahl U, Börsbo J, Schmidt C, Nilsson S, et al. (2017) The association between autonomic dysfunction, inflammation and atherosclerosis in men under investigation for carotid plaques. PLoS One 12(4): e0174974.

63. Pizzi C, Manzoli L, Mancini S, Bedetti G, Fontana F, et al. (2010) Autonomic nervous system, inflammation and preclinical carotid atherosclerosis in depressed subjects with coronary risk factors. Atherosclerosis 212(1): 292-298. 


\section{Current Research in Diabetes \& Obesity Journal} (C) Commons Attribution 4.0 Licens

BY DOI: 10.19080/CRDOJ.2018.09.555753
Your next submission with Juniper Publishers will reach you the below assets

- Quality Editorial service

- Swift Peer Review

- Reprints availability

- E-prints Service

- Manuscript Podcast for convenient understanding

- Global attainment for your research

- Manuscript accessibility in different formats ( Pdf, E-pub, Full Text, Audio)

- Unceasing customer service

Track the below URL for one-step submission https://juniperpublishers.com/online-submission.php 